\title{
Prebiotic Organic Microstructures
}

\author{
Marie-Paule Bassez • Yoshinori Takano • \\ Kensei Kobayashi
}

Received: 2 February 2012 / Accepted: 20 May 2012 /

Published online: 11 August 2012

C The Author(s) 2012. This article is published with open access at Springerlink.com

\begin{abstract}
Micro- and sub-micrometer spheres, tubules and fiber-filament soft structures have been synthesized in our experiments conducted with $3 \mathrm{MeV}$ proton irradiations of a mixture of simple inorganic constituents, $\mathrm{CO}, \mathrm{N}_{2}$ and $\mathrm{H}_{2} \mathrm{O}$. We analysed the irradiation products, with scanning electron microscopy (SEM) and atomic force microscopy (AFM). These laboratory organic structures produced a wide variety of proteinaceous and non-proteinaceous amino acids after $\mathrm{HCl}$ hydrolysis. The enantiomer analysis for $\mathrm{D}, \mathrm{L}$-alanine confirmed that the amino acids were abiotically synthesized during the laboratory experiment. We discuss the presence of $\mathrm{CO}_{2}$ and the production of $\mathrm{H}_{2}$ during exothermic processes of serpentinization and consequently we discuss the production of hydrothermal $\mathrm{CO}$ in a ferromagnesian silicate mineral environment. We also discuss the low intensity of the Earth's magnetic field during the Paleoarchaean Era and consequently we conclude that excitation sources arising from cosmic radiation were much more abundant during this Era. We then show that our laboratory prebiotic microstructures might be synthesized during the Archaean Eon, as a product of the serpentinization process of the rocks and of their mineral contents.
\end{abstract}

Keywords Origin of life · Prebiotic chemistry · Prebiotic signatures · Geochemistry · Analytical chemistry

M.-P. Bassez ( $\square)$

Département Chimie, Université de Strasbourg, 72 route du Rhin, 67400 Illkirch, France

e-mail: marie-paule.bassez@unistra.fr

Y. Takano

Institute of Biogeosciences, Japan Agency for Marine-Earth Science and Technology (JAMSTEC), 2-15 Natsushima, Yokosuka 237-0061, Japan

e-mail: takano@jamstec.go.jp

K. Kobayashi

Department of Chemistry and Biotechnology, Yokohama National University, 79-5 Tokiwadai,

Hodogaya-ku, Yokohama 240-8501, Japan

e-mail: kkensei@ynu.ac.jp 


\section{Introduction}

Experiments simulating the primitive Earth atmosphere were conducted on gaseous mixtures of $\mathrm{CO}, \mathrm{N}_{2} / \mathrm{NH}_{3}$ above liquid water irradiated with protons, helium ions, electrons, heavy ions, gamma and $\mathrm{X}$ and UV -rays, in a glass tube. Most of them led to proteinous and nonproteinous amino acids (Kobayashi et al. 2008). The first Kobayashi experiment irradiating with protons a gaseous mixture of $\mathrm{CO} /\left(\mathrm{CO}+\mathrm{CO}_{2}\right)$ and $\mathrm{N}_{2}$ over liquid $\mathrm{H}_{2} \mathrm{O}$ was performed in 1989 (Kobayashi et al. 1989, 1990). The resulting liquid aqueous solution was filtered through a membrane filter (pore size: $0.2 \mu \mathrm{m}$ ). The analysis of the remainder of the solution led to amino acids. Mixtures of $\mathrm{CO} /\left(\mathrm{CO}+\mathrm{CO}_{2}\right), \mathrm{N}_{2}, \mathrm{H}_{2} \mathrm{O}$ irradiated with 3 and $40 \mathrm{MeV}$ protons, with $65 \mathrm{MeV}$ helium nuclei and $400 \mathrm{MeV}$ electrons, also produce amino acids after $\mathrm{HCl}$ hydrolysis of the resulting aqueous solution (Kobayashi et al. 1998). These last experiments showed that products were independent of the kind of irradiating particles. They showed also that the formation rate of amino acids was determined by the number of carbon monoxide molecules. Mixtures of $\mathrm{CO}$ and $\mathrm{N}_{2}$ over liquid $\mathrm{H}_{2} \mathrm{O}$, irradiated with X-rays, led also to amino acids after freeze drying and $\mathrm{HCl}$ hydrolysis of the product aqueous solution (Takahashi et al. 1999). Mixtures of $\mathrm{CO}$ and $\mathrm{NH}_{3}$ over liquid water irradiated with protons also led to amino acids after $\mathrm{HCl}$ hydrolysis of the irradiation products (Takano et al. 2004a). Asymmetric syntheses of amino acid precursors have also been performed after proton irradiation of a $\mathrm{CO}, \mathrm{NH}_{3}, \mathrm{H}_{2} \mathrm{O}$ mixture, followed by irradiation with right and left ultraviolet circularly polarized light (Takano et al. 2007). None of the above cited experiments gave information on the morphology of the synthesized compounds.

Envisioning a laboratory synthesis of amino acids as a consequence of the process of serpentinization, with as reactant a solid phase such as mafic or ultramafic rocks or their iron mineral constituents, olivine and pyroxenes (Bassez 2008a, b, 2009), we first irradiated with protons, a gaseous mixture of $\mathrm{CO}, \mathrm{N}_{2}$ and water and we analysed the 3D-morphology of the products. We choosed $\mathrm{CO}$ instead of $\mathrm{CO}_{2}$ since earlier experiments irradiating with protons mixtures of $\mathrm{CO}_{2}, \mathrm{~N}_{2}$ and $\mathrm{H}_{2} \mathrm{O}$ did not produce amino acids (Kobayashi et al. 1989, 1998). And also, we considered that $\mathrm{CO}_{2}$ may be transformed into $\mathrm{CO}$ in a natural hydrothermal process of serpentinization (Seewald et al. 2006). Discussions of abiotic synthesis of organic molecules in hydrothermal systems have focused mainly on methane and hydrocarbons (Foustoukos and Seyfried 2004; McCollom and Seewald 2007). The abiotic synthesis of amino-acids in hydrothermal systems has been suggested but is not yet demonstrated.

Here we analyse for the first time the 3D-morphology and the chirality of the products synthesized during proton irradiation of a gaseous mixture of $\mathrm{CO}, \mathrm{N}_{2}$ and $\mathrm{H}_{2} \mathrm{O}$. We observe filamentous and spherical micro and sub-micrometer structures which produce amino acids after $\mathrm{HCl}$ hydrolysis. As criteria to differentiate abiotic synthesis from contamination of biogenic origin, we used the concept of chirality and we proceeded to enantiomer analysis after derivatization of the hydrolyzed product. We observed a racemic mixture of the most abundant chiral amino acid synthesized in this study D,L-alanine, thus eliminating a biogenic contamination. Considering geology with the presence of mafic and ultramafic ferromagnesian rocks, hydrothermal chemistry with the exothermic natural process of serpentinization and the release of $\mathrm{H}_{2}$, the high abundance of atmospheric $\mathrm{CO}_{2}$, energy arising from cosmic protons or cosmic gamma rays irradiating water or cosmic radiation components, we propose that these laboratory organic microstructures may have been synthesized during Archaean Eon. The results and discussions written in the present article have been posted on Nature Precedings on 21 July 2010 (Bassez and Takano 2010). A new version considering the Earth magnetic field has been presented on a poster at the ORIGINS 
conference in Montpellier in July 2011 and posted on Nature Precedings on 14 November 2011 (Bassez et al. 2011).

\section{Materials and Method}

Proton irradiation ( $3 \mathrm{MeV}$ ) was performed for $2 \mathrm{~h}$, at the Tokyo Institute of Technology using a Van de Graaff accelerator. The quantity of electricity for single irradiation run was 2 $\mathrm{mC}$. A Pyrex glass tube was filled with inorganic gas components consisting of 350 Torr carbon monoxide $(\mathrm{CO})$ and 350 Torr nitrogen $\left(\mathrm{N}_{2}\right)$ over $5 \mathrm{~mL}$ of distilled liquid water $\left(\mathrm{H}_{2} \mathrm{O}\right)$ which provided 20 Torr of water vapor at room temperature.

Ultra-pure grade carbon monoxide and dinitrogen gases were purchased from Nihon Sanso Co.. All glassware was heated in a high temperature oven (DR-22, Yamato Co., Tokyo, Japan) at $500{ }^{\circ} \mathrm{C}$ to eliminate any possible contaminants prior to use. Deionized water was further purified with a Millipore Milli-Q LaboSystem ${ }^{\mathrm{TM}}$ and a Millipore Simpli Lab-UV (Japan Millipore Ltd., Tokyo, Japan) to remove inorganic ions and organic contaminants.

The irradiation product analysis was conducted in the Institute of Biogeosciences, Japan Agency for Marine-Earth Science and Technology, JAMSTEC, in Yokosuka. After the surface polishing of sample plate for hydrophilic treatment by HDT-400 (JEOL), an aliquot of the unfiltered solution containing the irradiation products was gently dropped and dried at ambient temperature and ambient pressure in clean bench to obtain involatile organic matter. Morphological analysis was performed with scanning electron microscopy (SEM, JSM$6700 \mathrm{~F}$, JEOL: accelerating voltage $<5 \mathrm{kV})$ under low pressure $\left(<10^{-4} \mathrm{~Pa}\right)$. Additionally, we also conducted atomic force microscopy (AFM, Seico Instruments Inc., SII SPA 400 unit, Japan) by the non-contact mode. The gel filtration chromatograph (GFC) was composed of a high performance liquid chromatography (HPLC) pump (TOSOH DP-8020) and a UV detector (TOSOH UV-8020). The separation columns used were TSKgel G2000 SWxL $(7.8 \mathrm{~mm}$ i.d. $\times 300 \mathrm{~mm})$ for gel filtration, and Inertsil ODS-3 $(4.6 \mathrm{~mm}$ i.d. $\times 250 \mathrm{~mm})$ for reversed-phase chromatography (Takano et al. 2004a). The mobile phase was a mixture of $25 \mathrm{mM}$ acetonitrile $(25 \%)$ and $0.1 \%$ trifluoroacetic acid $(75 \%)$. Molecular weights were calibrated using several molecular weights of polyethylene glycol (PEG) and human serum albumin (Takano et al. 2004a). The aqueous solution containing the irradiation products was not filtered and an aliquot was hydrolyzed with $6 \mathrm{M} \mathrm{HCl}$ at $110{ }^{\circ} \mathrm{C}$ for $24 \mathrm{~h}$. Amino acids in the hydrolyzed fraction were analysed with an ion-exchanged HPLC system with analytical methods improved since the analysis of lunar samples (Kvenvolden et al. 1970; Kobayashi et al. 1990; Botta and Bada 2002; Takano et al. 2004a, b). The HPLC system used was composed of two high performance liquid chromatograph pumps (Shimadzu LC-10A), a cation exchange column (Shimpak ISC-07/S1504, $4 \mathrm{~mm}$ i.d. $\times 150 \mathrm{~mm}$ ), a post-column derivatization system with o-phthalaldehyde and N-acetyl-L-cystein, and a Shimadzu RF535 fluorometric detector (Takano et al. 2004b).

We also proceeded to enantiomer analysis after derivatization procedures to yield $\mathrm{N}$ pivaloyl- $(S)$-2-butyl esters $(\mathrm{NP} / S 2 \mathrm{Bu})$ of the amino acid diastereoisomers (Takano et al. 2009). The NP/S2Bu esters were identified by a gas chromatograph/mass spectrometry (GC/MS; Agilent Technologies 6890N/5973MSD). The capillary column used for GC was an HP-5 ms $(30 \mathrm{~m} \times 0.32 \mathrm{~mm}$ i.d., $0.52 \mu \mathrm{m}$ film thickness; Agilent Technologies $)$. The GC oven temperature was programmed as follows: initial temperature $40{ }^{\circ} \mathrm{C}$ for $4 \mathrm{~min}$, ramped up at $10{ }^{\circ} \mathrm{C} \min ^{-1}$ to $90{ }^{\circ} \mathrm{C}$, and ramped up at $5{ }^{\circ} \mathrm{C} \min ^{-1}$ to $220{ }^{\circ} \mathrm{C}$, where it was maintained for $10 \mathrm{~min}$. The MS was scanned over $\mathrm{m} / z$ of $50-550$ with the electron-impact mode set at $70 \mathrm{eV}$. 
In order to obtain the yield of amino acids, we used the G-value (the number of formed molecules per $100 \mathrm{eV}$ ) of glycine in the hydrolyzed products, because (i) glycine is the most abundant amino acid and (ii) it was demonstrated that glycine was formed in proportion to total energy deposit including particle and photon irradiation. Discussions of G-values as a function of cosmic rays energy can be found in Kobayashi et al. 1998.

\section{Results}

SEM (Fig. 1a, b) and AFM (Fig. 2a, b) were performed to observe three-dimensional morphological characteristics of the yellow-colored microstructures synthesized during the irradiation. SEM images show micro- and sub-micrometer spheres, tubules and fiber-filament soft tissues. AFM was used to observe the surface of these micro- and sub-microstructures. Figure $2 \mathrm{a}$ and $\mathrm{b}$ show AFM images of the same kind of structure. On Fig. 2a is observed a depression, $140 \mathrm{~nm}$ in depth and $1 \mu \mathrm{m}$ in width. On Fig. $2 \mathrm{~b}$ is observed a depression, $125 \mathrm{~nm}$ in depth and $0.5 \mu \mathrm{m}$ in width. Figure $2 \mathrm{a}$ shows the edges of the depression covered with protuberances which are irregular in shape. The striations observed on the white prominent parts of the depression edges (Fig. 2b) result most probably from an image of the probe tip on the depression slope and not

Fig. 1 a Three-Dimensional Scanning Electron Microscopy, 3D-SEM, images of the dried product, abiotically synthesized from a gas mixture of $\mathrm{CO}-\mathrm{N}_{2}-\mathrm{H}_{2} \mathrm{O}$ excited with $3 \mathrm{MeV}$ proton irradiation; bar is $1 \mu \mathrm{m}$, acceleration voltage $2.0 \mathrm{kV}$, magnification $\times 7,000$, working distance $8 \mathrm{~mm}$. b 3D-SEM, image of the dried proton irradiation product; bar is $1 \mu \mathrm{m}$, acceleration voltage $2.0 \mathrm{kV}$, magnification $\times 20,000$, working distance $8 \mathrm{~mm}$
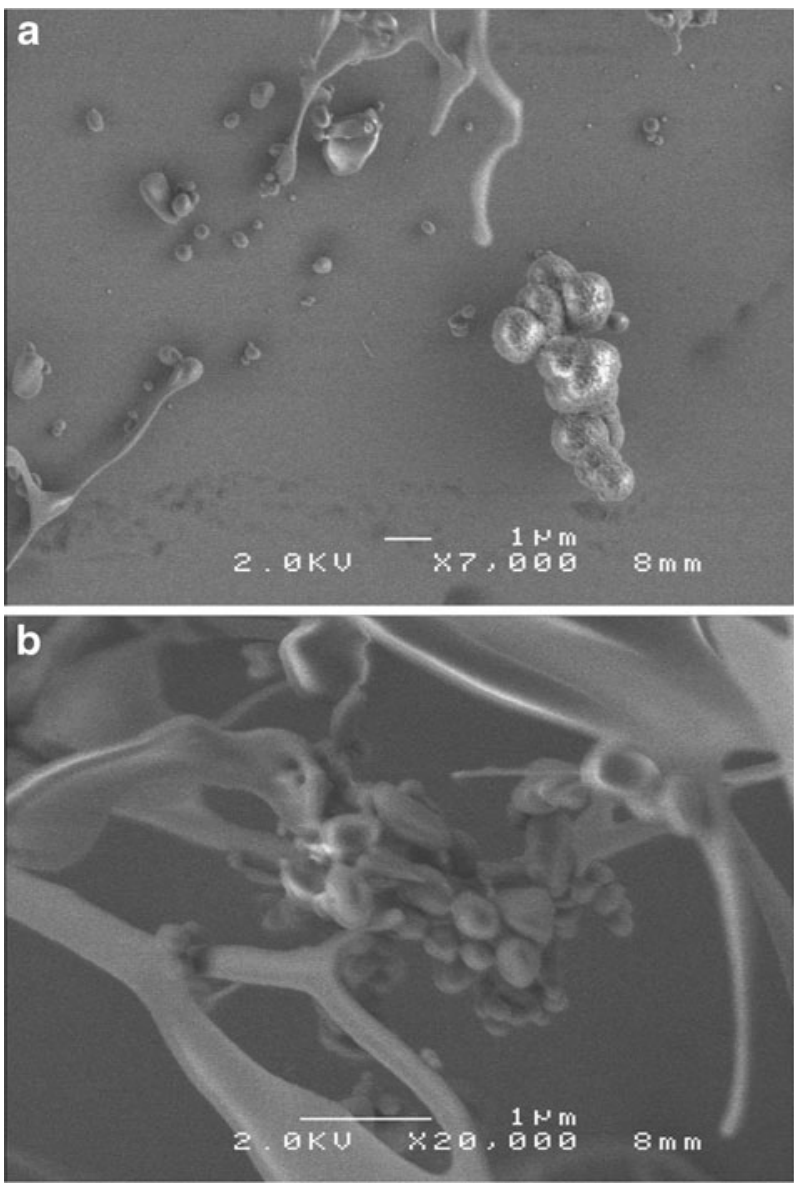
Fig. 2 a 3D-Atomic Force Microscopy, 3D-AFM, images of the dried product, abiotically synthesized from a gas mixture of CO- $\mathrm{N}_{2}-\mathrm{H}_{2} \mathrm{O}$, excited with $3 \mathrm{MeV}$ proton irradiation. b $3 \mathrm{D}$-AFM images of the same structure
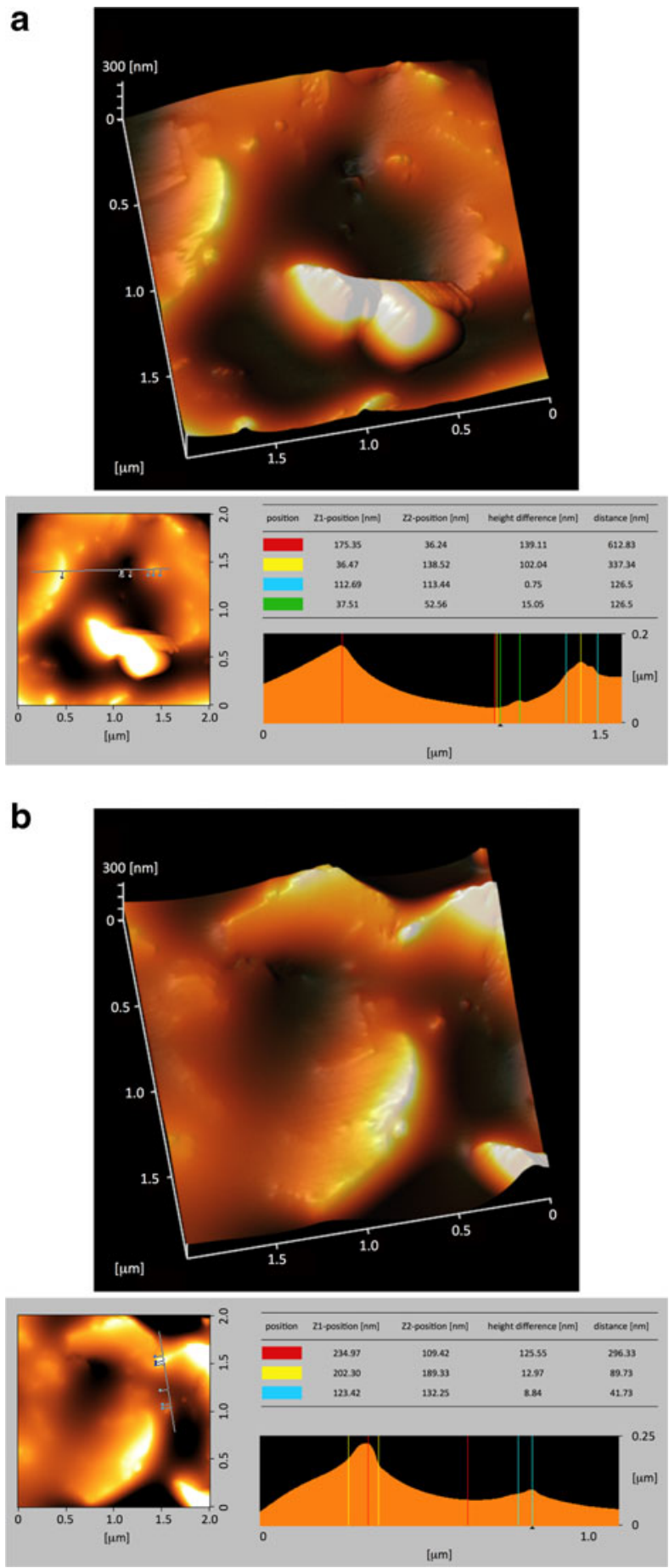
from an image of the structure surface. However, the depression is wide enough to say that the AFM images show the surface of the structures and are not an artifact image of the probe tip. The molecular weights of these organic microstructures, determined with GFC, are distributed between several hundred and a maximum of $3000 \mathrm{Da}$. A wide variety of amino acids were detected after $\mathrm{HCl}$ acid-hydrolysis of this dried aliquot (Fig. 3a, b). To eliminate possible contamination results, we conducted chiral analysis after derivatization of the hydrolyzed fraction (Takano et al. 2009). Figure 4 shows GC separation of N-pivaloyl-( $S$ )-2-butyl esters of D,L-alanine and glycine. The most abundant chiral amino acid, D,L-alanine, shows a racemic mixture produced by pristine abiotic chemical synthesis. Therefore, we exclude potential contamination on our organic analysis and we may conclude that the dried irradiation products are composed of abiogenic organic nano and microstructures.

Fig. 3 a Relative abundance of amino acids detected after acid hydrolysis of the dried irradiation product. Abbreviations. Gly, glycine; D,L-ala, D,L-alanine; $\mathrm{D}, \mathrm{L}-\alpha$-ABA, D,L- $\alpha$-aminobutyric acid; D,L-asp, D,L-aspartic acid; $\beta$-ala, $\beta$-alanine; $D, L$ ser, D,L-serine; others, including very minor amino acids. b Relative abundance of amino acids on a logarithmic scale a
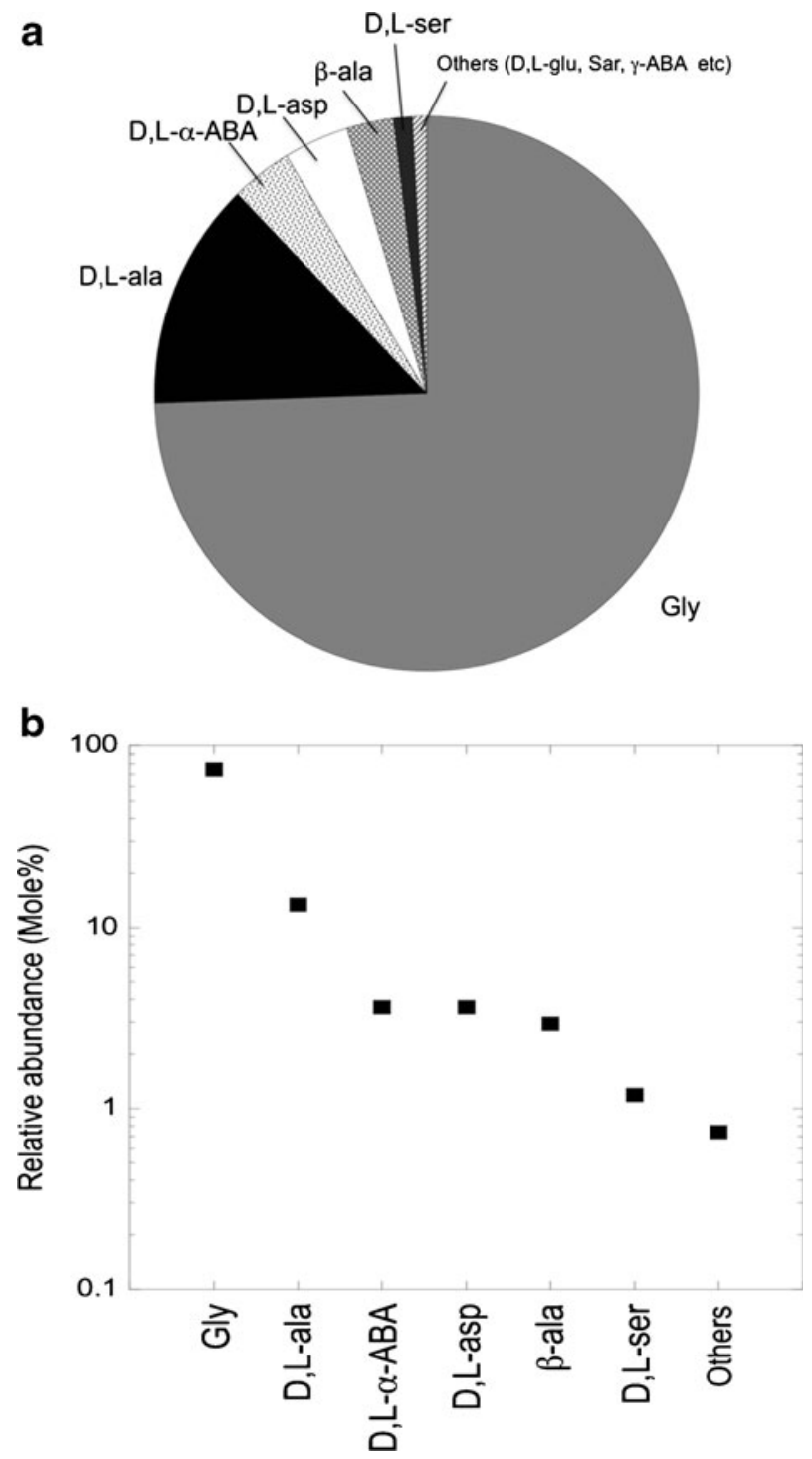


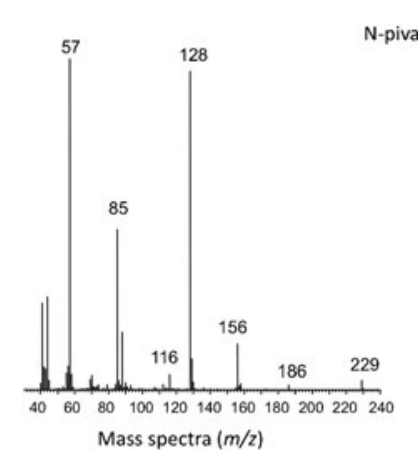

-pivaloyl-(S)-2-butyl esters of D-, L- alanine (* stands for chiral center)
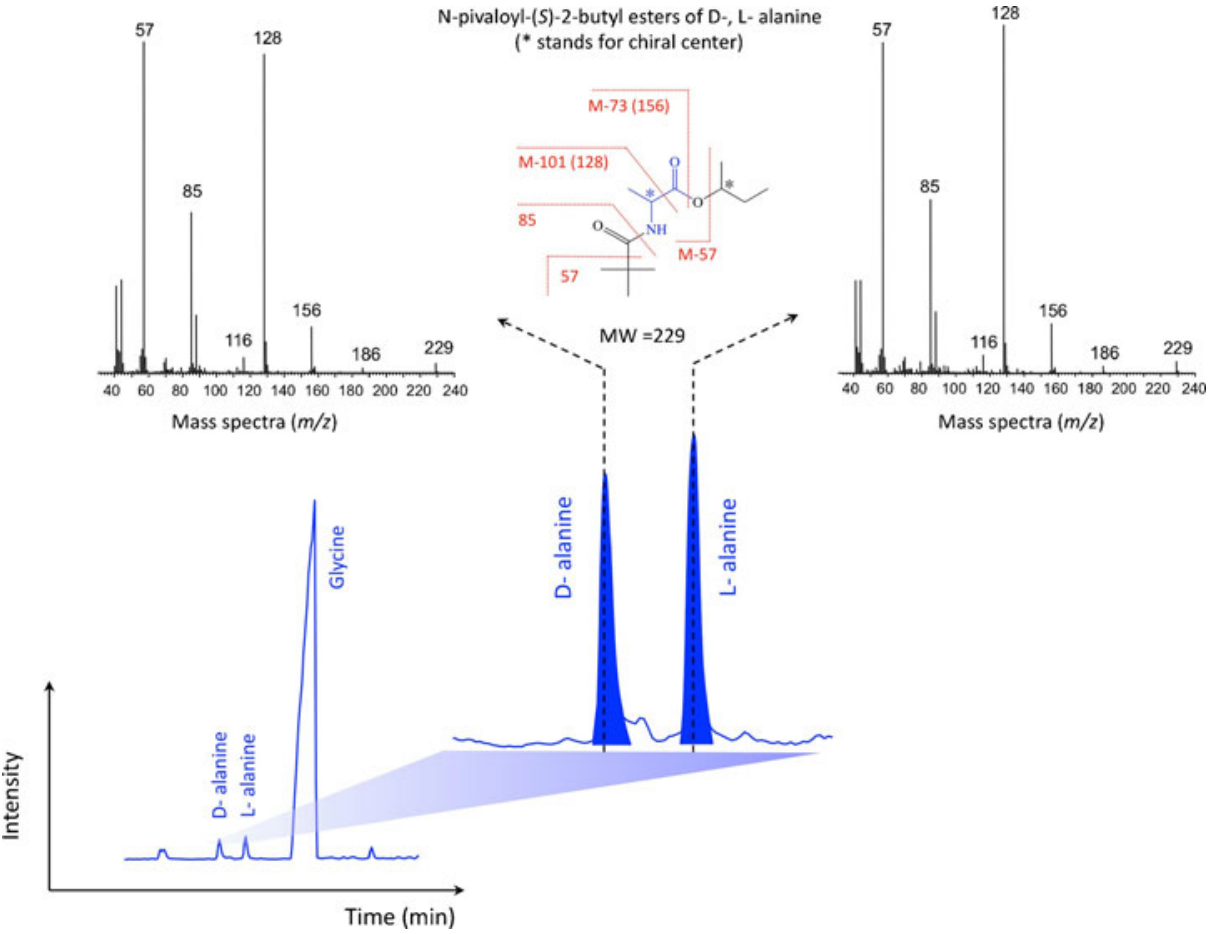

Fig. 4 Gas chromatograph (GC) separation and its mass fragment pattern of the N-pivaloyl-(S)-2-butyl esters of D,L-alanine

It is to be noticed that we conducted earlier same analytical procedures for analyses of peridotite rocks which were dredged on the ocean floor of the mid-atlantic ridge (MAR) (Bassez et al. 2009). Non racemic mixtures of amino acids were obtained leading to the conclusion of sedimentary biological origin for the observed amino acids. These two opposite conclusions for similar analytical procedures applied to abiotic synthesis and rock analysis, also prove that our analytical procedures are exempt of biological contamination. The amino acids synthesized in this study include glycine, alanine, aspartic acid, serine and the non-proteinous amino acids $\beta$-alanine (BALA), $\alpha$-aminobutyric (ABA) acid and $\gamma$ aminobutyric acid (GABA). Glycine was most abundant followed by D,L-alanine, D,L- $\alpha$ aminobutyric acid, D,L-aspartic acid, $\beta$-alanine and D,L-serine, in logarithmic decrease.

The energetic yield of glycine normalized by G-value (number of synthesized molecules per $100 \mathrm{eV}$ absorbed) in the present proton irradiation experiment was 0.02 (cf. Kobayashi et al. supporting data 1998).

\section{Discussion}

Our structures are synthesized when gaseous $\mathrm{CO}$ and $\mathrm{N}_{2}$ are present over liquid water. On Earth, the source of $\mathrm{CO}$ could be hydrothermal, arising from the transformation of $\mathrm{CO}_{2}$ into $\mathrm{CO}\left(\mathrm{CO}_{2}+\mathrm{H}_{2} \leftrightarrow \mathrm{CO}+\mathrm{H}_{2} \mathrm{O}\right)$. The temperature of the experiment which led to the formation of $\mathrm{CO}$ and $\mathrm{CH}_{4}$ from a mixture of $\mathrm{CO}_{2}$ dissolved in flowing seawater, of gaseous $\mathrm{H}_{2}$ and of magnetite was conducted at $250{ }^{\circ} \mathrm{C}-300{ }^{\circ} \mathrm{C}$ and $250 \mathrm{bar}$ (Fu and Seyfried 2009). Theoretical 
calculations showed that at $35 \mathrm{MPa}, \mathrm{H}_{2}$ production occurred during serpentinization of ultramafic rocks, between 200 and $315^{\circ} \mathrm{C}$ (McCollom and Bach 2009) and that serpentinization may occur at temperatures below $300{ }^{\circ} \mathrm{C}$ (Klein and Bach 2009). $\mathrm{H}_{2}$ was also generated in a recent experiment conducted at $300{ }^{\circ} \mathrm{C}$ and 500 bars on hydrolysis of komatiite glass (Yoshizaki et al. 2009). At those temperatures, $\mathrm{CO}$ is present in both aqueous and gaseous phases. Consequently, $\mathrm{CO}$ is available in the gaseous phase in hydrothermal environments where olivine encounters serpentinization, producing $\mathrm{H}_{2}$ and magnetite. Olivine and pyroxenes minerals found in mafic and ultramafic rocks, are iron and magnesium silicates. Exothermic reactions of diverse olivine $(\mathrm{Mg}, \mathrm{Fe})_{2} \mathrm{SiO}_{4}$ and pyroxenes $(\mathrm{Y}, \mathrm{Fe})_{\mathrm{x}} \mathrm{Si}_{2} \mathrm{O}_{6}$ with $\mathrm{H}_{2} \mathrm{O}$ and $\mathrm{CO}_{2}$ lead to products such as quartz, magnetite, serpentine, calcium carbonate, $\mathrm{H}_{2}$ and recently $\mathrm{CO}$ (Fu and Seyfried 2009). Even if the serpentinization reactions of all diverse olivine and pyroxenes have not yet been studied in detail, it is known that they are highly exothermic. Geological sites where exothermic mineral transformation occurs with a release of $\mathrm{H}_{2}$ are consequently appropriate sites for the transformation of $\mathrm{CO}_{2}$ into $\mathrm{CO}$. In their environment, synthesis of abiotic organic microstructures might consecutively occur.

A recent article shows that release of $\mathrm{H}_{2}$ occurs at low temperature, 30 to $70{ }^{\circ} \mathrm{C}$, when olivine containing magnetite and chromite is hydrolyzed (Neubeck et al. 2011). However at these temperatures, the formation of $\mathrm{CO}$ from $\mathrm{CO}_{2}$ is not thermodynamically favorable. Indeed, earlier experimental investigations of the $\mathrm{CO}$ transformation showed that substantially higher $\mathrm{CO}$ concentrations occur at $350{ }^{\circ} \mathrm{C}$ rather than at $150{ }^{\circ} \mathrm{C}$ (Seewald et al. 2006).

It is consequently plausible to propose that dinitrogen embedded in a ferromagnesian geological environment may react with $\mathrm{CO}$ and $\mathrm{H}_{2} \mathrm{O}$ to form molecules which may assemble during a dryness period into microspheres, filaments and tubules containing organic structures such as those synthesized in our laboratory experiment.

The abundance of $\mathrm{CO}_{2}$ was higher during Archaean Eon. The atmospheric partial pressure of $\mathrm{CO}_{2}$ was several times higher $3.2 \mathrm{Ga}$ ago than present-day values (Hessler et al. 2004). The source of excitation, protons, was also higher. Protons arise from cosmic radiation or from gamma rays included in cosmic radiation which induce protons through water radiolysis. In Paleoarchaean Era, 3.5 Ga ago, the Earth magnetic field was much lower than in Phanerozoic Eon, Holocene Epoch. A very low equatorial paleointensity of $\sim 5 \mu \mathrm{T}$ at c.a. 3.5 Ga was reported (Hale 1987; Yoshihara and Hamano 2002) which corresponds to $17 \%$ of the present day value. Cosmic radiation and its components could consequently easily reach the surface of the Earth. Little is known about coronal mass ejection of the Paleoarchaean Sun. However, a proton source from cosmic radiation reaching the surface of the Earth seems more probable than a proton source induced by gamma rays arising from extinct radionuclides. Indeed, the amount of radioactivity brought by the late heavy bombardment has been recently controversial. It is to be noticed that an excitation source arising from cosmic radiation, such as protons, helium nuclei and electrons would most probably produce the same kind of structures since earlier experiments (Kobayashi et al. 1998) showed that products were independent of the nature of the irradiating particles.

Experiments on the thermal alteration of these abiotic structures have been recently conducted (Kurihara et al. 2012). They show the formation of organic aggregates with aromatic carbon, at temperatures between 200 and $400{ }^{\circ} \mathrm{C}$ and under fluid pressure of $25 \mathrm{MPa}$.

\section{Conclusion}

We demonstrate that organic micro and sub-microstructures are synthesized during proton irradiation of a gaseous mixture of $\mathrm{CO}, \mathrm{N}_{2}, \mathrm{H}_{2} \mathrm{O}$. Their shapes vary from spheres to 
filaments and they produce amino acids after $\mathrm{HCl}$ hydrolysis. The enantiomer analysis for $\mathrm{D}$, L-alanine confirmed that the amino acids were abiotically synthesized during the laboratory experiment. Analysing hydrothermal, chemical and mineral conditions of natural formation on Earth, we show that these prebiotic microstructures might be synthesized during Archaean Eon, from a mixture of $\mathrm{CO}, \mathrm{N}_{2}$ and $\mathrm{H}_{2} \mathrm{O}$, in hydrothermal silicate environments and under an excitation source arising from cosmic radiation which existed in higher intensity $3.5 \mathrm{Ga}$ ago than Phanerozoic Eon, Holocene Epoch. We show that these prebiotic microstructures might be formed as a product of the exothermic hydrolysis of the rocks and of their mineral contents during the process of serpentinization.

Amino acid precursors were first obtained from proton irradiation of $\mathrm{CO}, \mathrm{N}_{2}, \mathrm{H}_{2} \mathrm{O}$ in 1989 (Kobayashi et al. 1989). Since that time, the formation of these organic molecules was discussed in primitive atmospheres rich in $\mathrm{CO}_{2}$ and in $\mathrm{CO}$ (Kobayashi et al. 1998; Miyakawa et al. 2002). Now we advance a step further, considering hydrothermal formation of $\mathrm{CO}$ as a product of the transformation of $\mathrm{CO}_{2}$ in geological sites where ferromagnesian silicate minerals encounter the process of serpentinization with the hydrothermal release of $\mathrm{H}_{2}$.

We suggest that a search for such organic micro and sub-microstructures, inside or nearby serpentinised rocks on Earth and on Mars, could be envisioned. The organic geochemistry of these rocks has been very little studied (Bassez et al. 2009). A discovery of such structures would confirm the hypothesis concerning prebiotic formation of amino acids near hydrothermal sites where olivine encounters serpentinization and considering a proton excitation source from cosmic radiation or as a product of water radiolysis (Bassez 2008a, b, 2009).

Acknowledgments The authors thank Katsunori Kawasaki (Tokyo Institute of Technology) for the experimental support and Naohiko Ohkouchi (Japan Agency for Marine-Earth Science and Technology) for discussions. They thank also Bernard Marty (Institut Universitaire de France et Ecole Nationale Supérieure de Géologie, Nancy) for discussions on the late heavy bombardment. Special thanks are addressed to Irène Revenko, Asylum Research, for her help in the description of the AFM images. This research was partly supported by the Japan Society for the Promotion of Science (Y.T), and a Grant-in-Aid for Creative Scientific Research (19GS0211).

Open Access This article is distributed under the terms of the Creative Commons Attribution License which permits any use, distribution, and reproduction in any medium, provided the original author(s) and the source are credited.

\section{References}

Bassez MP (2008a) Synthèse prébiotique dans les conditions hydrothermales. CNRIUT'08, http://liris.cnrs.fr/ $\sim$ cnriut08/actes/. Accessed 29 May, période1, C:1-8

Bassez MP (2008b) Prebiotic synthesis under hydrothermal conditions. Orig Life Evol Biosph 39(3-4):223225 (2009); proceedings of the 2008 ISSOL conference, Firenze

Bassez MP (2009) Synthèse prébiotique dans les conditions hydrothermales. C R Chimie 12(6-7):801-807

Bassez MP, Takano Y (2010) Prebiotic organic globules. Available from Nature Precedings $<$ http://hdl.handle.net/ 10101/npre.2010.4694.1>(2010)

Bassez MP, Takano Y, Ohkouchi N (2009) Organic analysis of peridotite rocks from Ashadze and Logatchev hydrothermal sites. Int J Mol Sci 10(7):2986-2998

Bassez MP, Takano Y, Kobayashi K (2011) Prebiotic organic microstructures. Available from Nature Precedings $<$ http://hdl.handle.net/10101/npre.2011.4694.2> (2011)

Botta O, Bada JL (2002) Extraterrestrial organic compounds in meteorites. Surv Geophys 23:411-467 
Foustoukos DI, Seyfried WE (2004) Hydrocarbons in hydrothermal vent fluids: the role of chromium-bearing catalysts. Science 304:1002-1005

Fu Q, Seyfried WE Jr (2009) Experimental study of abiotic synthesis processes in a hydrothermal flow system: implications for organic matter formation in extraterrestrial environments. 40th lunar and planetary science conference abstracts: 2504

Hale CJ (1987) The intensity of the geomagnetic field at $3.5 \mathrm{Ga}$ : paleointensity results from the Komati formation, Barberton mountain land, South Africa. Earth and Planet. Sci Lett 86:354-364

Hessler AM, Lowe DR, Jones RL, Bird DK (2004) A lower limit for the atmospheric carbon dioxide levels 3.2 billion years ago. Nature 428:736-738

Klein F, Bach W (2009) Fe-Ni-Co-O-S phase relations in peridotite-seawater interactions. J Petrol 50:37-59

Kobayashi K, Oshima T, Yanagawa H (1989) Abiotic synthesis of amino acids by proton irradiation of a mixture of carbon monoxide, nitrogen and water. Chem Lett 18(9):1527-1530

Kobayashi K, Kaneko T, Saito T, Oshima T (1990) Abiotic synthesis of amino acids and imidazole by proton irradiation of simulated primitive earth atmospheres. Orig Life Evol Biosph 22(2):99-109

Kobayashi K, Kaneko T, Saito T, Oshima T (1998) Amino acid formation in gas mixtures by particle irradiation. Orig Life Evol Biosph 28:155-165

Kobayashi K, Ogawa T, Tonishi H, Kaneko T, Takano Y, Takahashi JI, Saito T, Muramatsu Y, Yoshida S, Utsumi Y (2008) Synthesis of amino acid precursors from simulated interstellar media by high-energy particles or photons. Electron Commun Japan 91(3):15-21

Kurihara H, Yabuta H, Kaneko T, Obayashi Y, TakanoY Kobayashi K (2012) Characterisation of organic aggregates formed by heating products of simulated primitive earth atmosphere experiments. Chem Lett 41:441-443

Kvenvolden K, Lawless J, Pering K, Peterson E, Flores J, Ponnamperuma C, Kaplan IR, Moore C (1970) Evidence for extraterrestrial amino-acids and hydrocarbons in the Murchison meteorite. Nature 228:923-926

McCollom T, Bach W (2009) Thermodynamic constraints on hydrogen generation during serpentinization of ultramafic rocks. Geochim Cosmochim Acta 73:856-875

McCollom T, Seewald JS (2007) Abiotic synthesis of organic compounds in deep-sea hydrothermal environments. Chem Rev 107:382-401

Miyakawa S, Yamanashi H, Kobayashi K, Cleaves HJ, Miller LS (2002) Prebiotic synthesis from CO atmospheres: implications for the origins of Life. PNAS 99(23):14628-14631

Neubeck A, Thanh Duc N, Bastviken D, Crill P, Holm GN (2011) Formation of H2 and CH4 by weathering of olivine at temperatures between 30 and 70 degrees C. Geochem. Trans. 12:6.

Seewald SL, Zolotov ML, McCollom T (2006) Experimental investigation of single carbon compounds under hydrothermal conditions. Geochim Cosmochim Acta 70:446-460

Takahashi J, Masuda H, Kaneko T, Kobayashi K, Saito T, Hosokawa T, Utsumi Y (1999) Abiotic synthesis of amino acids by X-rays irradiation of simple inorganic gases. Appl Phys Lett 74:877-879

Takano Y, Ohashi A, Kaneko T, Kobayashi K (2004a) Abiotic synthesis of high-molecular weight organics from an inorganic gas mixture of carbon monoxide, ammonia and water by $3 \mathrm{MeV}$ proton irradiation. Appl Phys Lett 84(8):1410-1412

Takano Y, Kobayashi K, Yamanaka T, Marumo K, Urabe T (2004b) Amino acids in the $308{ }^{\circ} \mathrm{C}$ deep-sea hydrothermal system of the Suiyo Seamount, Izu-Bonin Arc, Pacific Ocean. Earth Planet Sci Lett 219:147-153

Takano Y, Takahashi J, Kaneko T, Marumo K, Kobayashi K (2007) Asymmetric synthesis of amino acid precursors in interstellar complex organics by circularly polarized light. Earth Planet Sci Lett 254:106-114

Takano Y, Chikaraishi Y, Ogawa ON, Kitazato H, Ohkouchi N (2009) Compound-specific nitrogen isotope analysis of D-alanine, L-alanine and valine: application of diastereomer separation to delta $15 \mathrm{~N}$ and microbial peptidoglycan studies. Anal Chem 81:394-399

Yoshihara A, Hamano Y (2002) Paleomagnetic constraints on the Archean geomagnetic field intensity obtained from komatiites of the Barberton and Belingwe greenstone belts, South Africa and Zimbabwe. Precambrian Res 131:111-142

Yoshizaki M, Shibuya T, Suzuki K, Shimizu K, Nakamura K, Takai K, Omori S, Maruyama S (2009) $\mathrm{H}_{2}$ generation by experimental hydrothermal alteration of komatiitic glass at $300{ }^{\circ} \mathrm{C}$ and 500 bars: a preliminary result from on-going experiment. Geochem J 43:e17-e22 